Sm 1989/15

\title{
ELECTROPHORETIC DEPOSITION OF ALUMINA FROM NON-AQUEOUS DISPERSIONS
}

\author{
R. Naß, W. Storch, H. Schmidt
}

Fraunhofer-Institut für Silicatforschung, Neunerplatz 2, D-8700 Würzburg, Federa! Republic of Germany

F. Harbach, R. Neeff and H. Nienburg

Asea Brown Boveri AG, D-6900 Heidelberg, Federal Republic of Germany

\begin{abstract}
Alumina has been deposited from an ethanolic suspension of commercial alumina powder stabilized with polyacrylic acid. The process has been studied by systematical variation of the deposition conditions and the properties of the suspensions. The microstructure of the deposited green plates is homogeneous except a thin porous layer $(200 \mathrm{~mm})$ at the electrode facing side. After sintering this porous layer is still present and causes a lower fracture strength of the electrode facing side in comparison to the solvent facing side of the compact. Methods for optimizing the microstructure are discussed.
\end{abstract}

\section{INTRODUCTION}

The production of ceramic components with good mechanical properties and reliability requires a fine and homogenous microstructure without critical defects in the sintered compact. This property can be improved by use of fine and ultrafine powders and for this reason submicron powders are of increasing interest. Since the processing of fine powders by conventional forming techniques is difficult, it is necessary to adapt the forming technique to the special properties of the powders. One technique is the electrophoretic deposition of ceramic powders from suspensions which is known for a long time /1-4/. But until now no attempts have been made to study this method with regard to the improvement of homogeneity and reliablity of ceramic compacts. In the present paper we will report about some fundamental correlations of the parameters which determine the electrophoretic deposition of alumina from non-aqueous suspensions and the resulting microstructure of the green compact as well as the strength of the sintered bodies. Non-aqueous suspensions were used to avoid the formation of gas bubbles by electrolysis of water. 


\section{EXPERIMENTAL}

The suspensions were prepared by ultrasonic agitation /5/ from commercial alumina powder (Alcoa A16SG) in a mixture of ethanol, water and polyacrylic acid (PAA) as the suspending agent. The alumina content was varied between 10 and 60 wt. $-q$ and the concentration of PAA ranged from 1.2 to 2.0 wt. -8 referring to the Alumina content.

Deposition experiments were performed in a cylindrical cell with $50 \mathrm{~mm}$ diameter and variable electrode distance up to $100 \mathrm{~mm}$. The applied voltage was changed between 10 and $300 \mathrm{~V}$ and the deposition time was varied between 2 and 25 minutes. The direction of deposition was parallel to the field of gravity. The green plates ( $3 \mathrm{~mm}$ thickness) were dried at $50{ }^{\circ} \mathrm{C}$ and a standard procedure was used for sintering $\left(1640^{\circ} \mathrm{C}, 10 \mathrm{~min}\right)$. The particle size distribution in the suspension was determined by sedimentation and after a sedimentation time of 16 hours particles larger than $1 \mu \mathrm{m}$ were separated. All suspensions studied in this paper were treated in this way before using them for deposition experiments. The zeta-potential was determined by measuring the movement of the boundary surface in a U-tube in an electric field.

\section{RESULTS AND DISCUSSION}

\section{Electrophoresis:}

Electrophoresis is based on the movement of charged particles in a liquid caused by an electric field. The surface charge of the alumina particles in the suspension is obtained by polyacrylic acid which is stucked on the particle surface. In addition to this, the PAA serves as a binder for the deposited particles. In a first approximation the deposited mass can be described by equation (1) which is a simplification of the more complicated description given by $/ 6 /$.

$$
\begin{aligned}
& m(t)=A \cdot c \cdot t \cdot U \cdot \epsilon \cdot z /(n \cdot d) \\
& \text { A: electrode area U: applied voltage } \\
& c \text { : powder concentration } \mathrm{Z} \text { : zeta-potential } \\
& t \text { : time of deposition } n \text { : viscosity } \\
& \epsilon \text { : permittivity } d \text { : electrode distance }
\end{aligned}
$$

This equation shows that the deposited mass depends on two different sets of parameters. The first is directly correlated to the suspension properties as the solid content, the zeta-potential, the permittivity and the viscosity. The second one belongs only to the deposition conditions as electrode area and distance, time of deposition and the applied voltage. The parameters which describe the deposition (see eq. 1) were investigated. 


\section{Suspension properties:}

The electrophoretic deposition of green compacts requires stable suspension as well as high deposition rates for an economical processing. For these reasons the suspension stability was optimized including high desposition rates. According to eq. I the following parameters were optimized: solid content (a high content was desired), zetapotential, PAA concentration, permittivity and viscosity. Since these parameters are not independent of each other, the influence of the PAA concentration and the solid content was investigated at first. It was found that the zeta-potential is very sensitive to the PAA-concentration and the solid content. The highest values (-38 to $-44 \mathrm{mV}$ ) are obtained at 1.3 to 1.5 wt. -8 PAA for alumina content of 40 wt. $-q$. The variation of the alumina concentration between 20 and 40 wt. -8 at constant PAA concentration $(1.4$ wt. -8$)$ caused a zeta-potential change between -44 to $-48 \mathrm{mV}$. The permittivity does not depend on the PAA content and decreases from 27.2 to 22.1 with the alumina content increasing from 10 to $60 \mathrm{wt} .-\mathrm{q}$. The viscosity depends only on the alumina content and increases from 1.3 to $4.4 \mathrm{mPa}^{\circ} \mathrm{s}$ (10 to $60 \mathrm{wt} .-\frac{q}{8}$ alumina).

\section{Deposition rates:}

The deposition rate has been studied as a function of the applied voltage and the alumina content. The suggested (eq. 1) linear relationship between deposited mass on the one and voltage and time on the other side could be proved, as shown in fig. 1 and 2. With increasing alumina content the deposited mass for constant time or voltage increases.

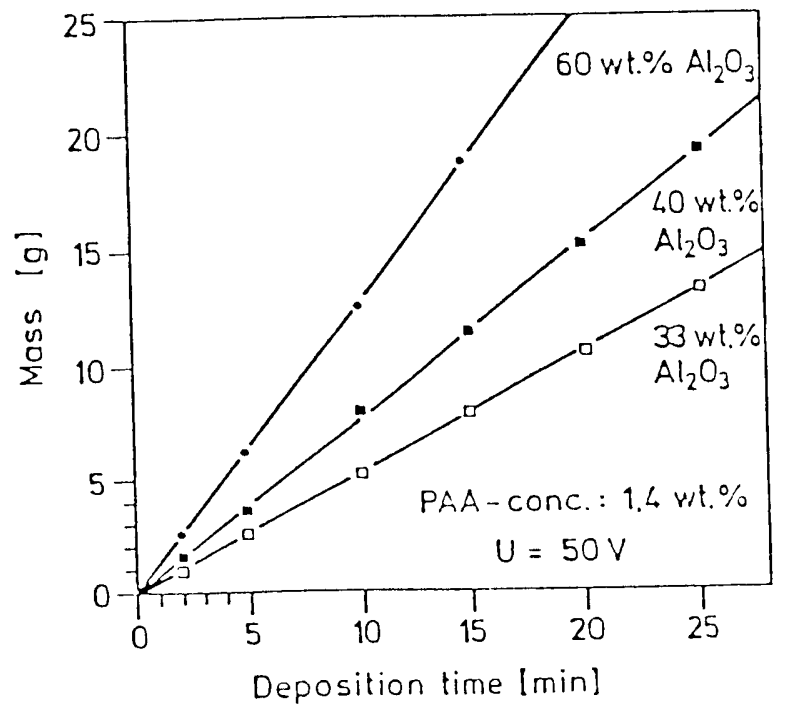

Fig. 1 Deposited mass as function of the deposition time for different alumina contents PAA-conc.: 1.4 wt. -8 , applied voltage: $50 \mathrm{~V}$ 


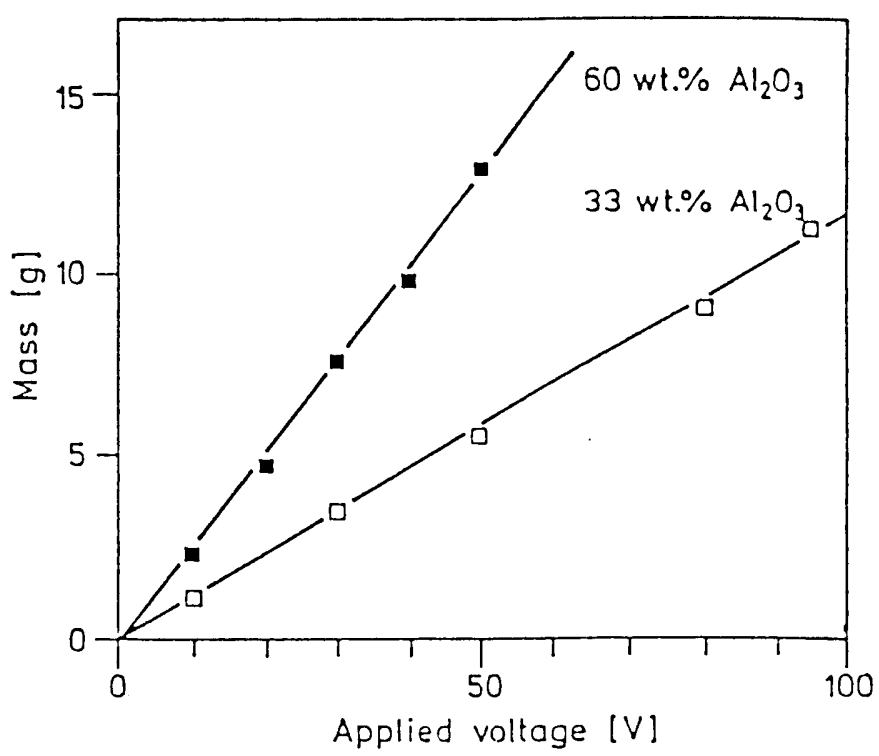

Fig. 2 Deposited mass as a function of the applied voltage for different alumina concentrations PAA-conc.: $1.4 \mathrm{wt}-\mathrm{q}$, deposition time: $10 \mathrm{~min}$

Characterization of the green plates:

The microstructure of the green plates was investigated by scanning electron microscopy (SEM). The solvent facing side of the green plate ( $f$ ig. 3 a) exhibits a homogenous microstructure with dense packed particles. In contrast the microstructure of the electrode facing side (fig. 3 b) is more heterogenous caused by agglomerates and large pores. This unexpected behavior was studied by further experiments and it could be shown that this type of surface microstructure is not primarily caused by the removal of the green plate from the electrode. Furthermore the surface is not affected by the suspension parameters and is not caused by a possible electrolysis of water leading to the formation of gas bubbles. From the present state of our knowledge the porous microstructure of the electrode side is directly connected to the deposition mechanisms, as it will be shown later. 


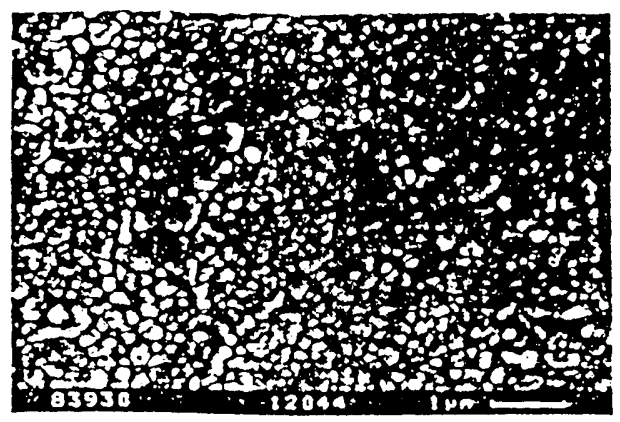

a)

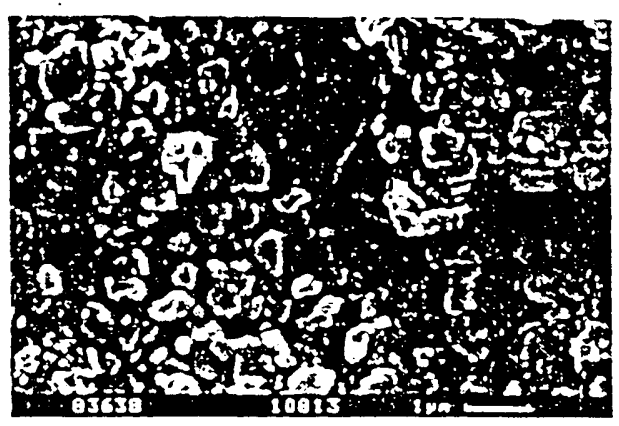

b)

Fig. 3 SEM-microgaphes of green plate

a: solvent facing side, b: electrode facing side

In order to determine the depth profile of the porous layer of the electrode facing side several layers with varying thicknesses were deposited, starting with $0.2 \mathrm{~mm}$ and increasing the layer thickness up to $1.5 \mathrm{~mm}$. The porosity of the different layers was measured by the $\mathrm{Hg}$-penetration method. After calculating the average plate density as a function of the thickness, the differential density can be calculated according to eq. (2):

$$
\mathrm{p}_{\mathrm{d}} \cdot \mathrm{d}=\Sigma \mathrm{p}_{\mathrm{i}} \cdot \mathrm{d}_{\mathrm{i}} \quad \mathrm{i}=1 \text { to } \mathrm{n}
$$

$\mathrm{p}_{\mathrm{d}}$ : density of the deposited layer

$\mathrm{d}^{\mathrm{d}}$ : thickness of the deposited layer

$\mathrm{p}_{i}$ : differential density

$\mathrm{d}_{i}$ : differential thickness

The average values of the differential densities $p_{i}$ as a function of the plate thickness are shown in fig. 4 .

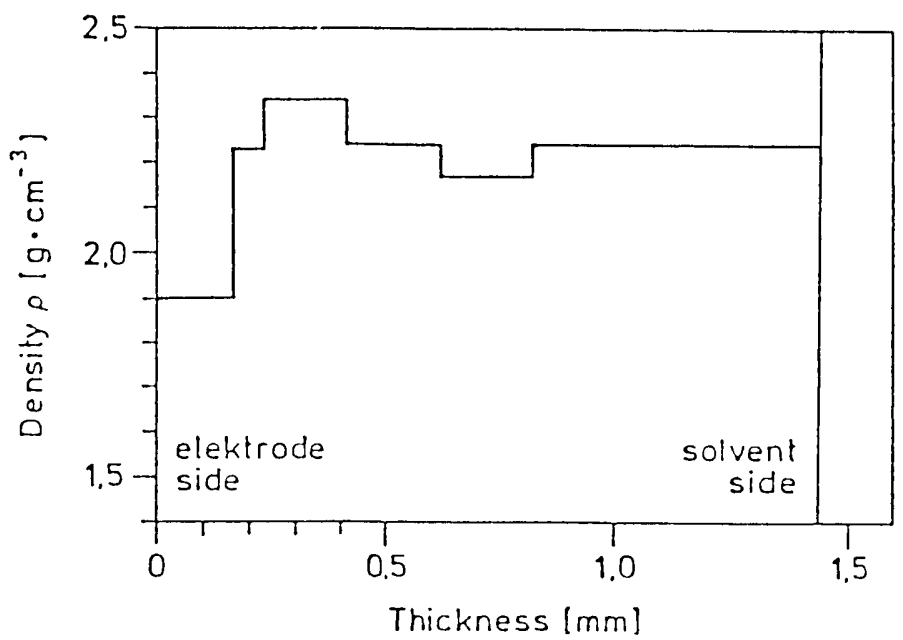

Fig. 4 Differential density as a function of the plate thickness 
It is obvious that the first layer $(200 \mu \mathrm{m})$ is significantly less dense than the overall density of the plate. The pore size distribution (determined by $\mathrm{Hg}$-porosimetry) of the first layer showed a higher number of pores greater than $10 \mu \mathrm{m}$ too, which is in agreement with the SEM-micrographs. The density of the porous layer ${ }_{3}$ is $1.9 \mathrm{~g} / \mathrm{cm}^{3}$ and density of a green compact is $2.25 \mathrm{~g} / \mathrm{cm}^{3}$. The formation of a porous layer was observed for different suspensions and deposition parameters. To reduce the porous layer thickness the influence of the deposition voltage was studied for a standard suspension (1.4 wt-q PAA, 33 wt-q alumina) and a constant electrode distance $(30 \mathrm{~mm})$. The results are shown in fig. 5. The density of the first deposited layer increases from 10 to $100 \mathrm{~V}$ and decreaşes slowly up to $300 \mathrm{~V}$. The maximum density $\left(2.05 \mathrm{~g} / \mathrm{cm}^{3}\right)$ is achieved at $100 \mathrm{~V}$. The influence of the applied voltage on the density of the thicker layers is not so distinct. The reasons for the formation of porous layers with a distinct thickness may be attributed to the mechanism of the deposition process and the discharge of the particles. However, this assumption has to be proved by further experiments.

Fracture strength of sintered plates:

The fracture strength was determined by a double ring test to get information about the microstructural defects of the sintered plates. Therefore both sides of the plates were tested under tension stress. The results are represented in a Weibull-plot in fig. 6 .

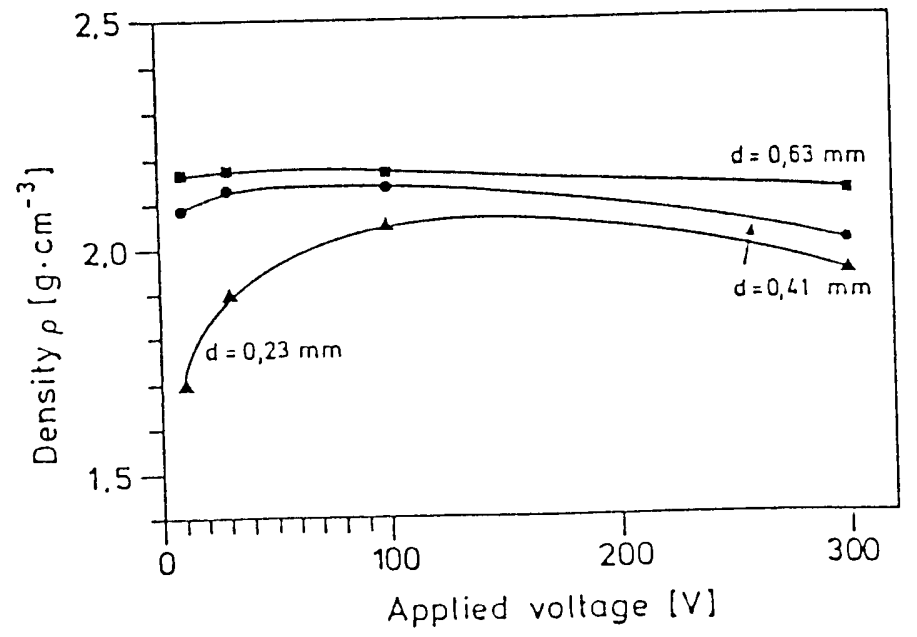

Fig. 5 Density as a function of the applied voltage for different green layer thicknesses 
The average of the fracture strength of the solvent side is $442 \mathrm{MPa}$, in comparison with $344 \mathrm{MPa}$ of the electrode side. The lower strength of the electrode side is due to its surface defects formed in the green state, which are also responsible for the low Weibull modulus of about 5 .

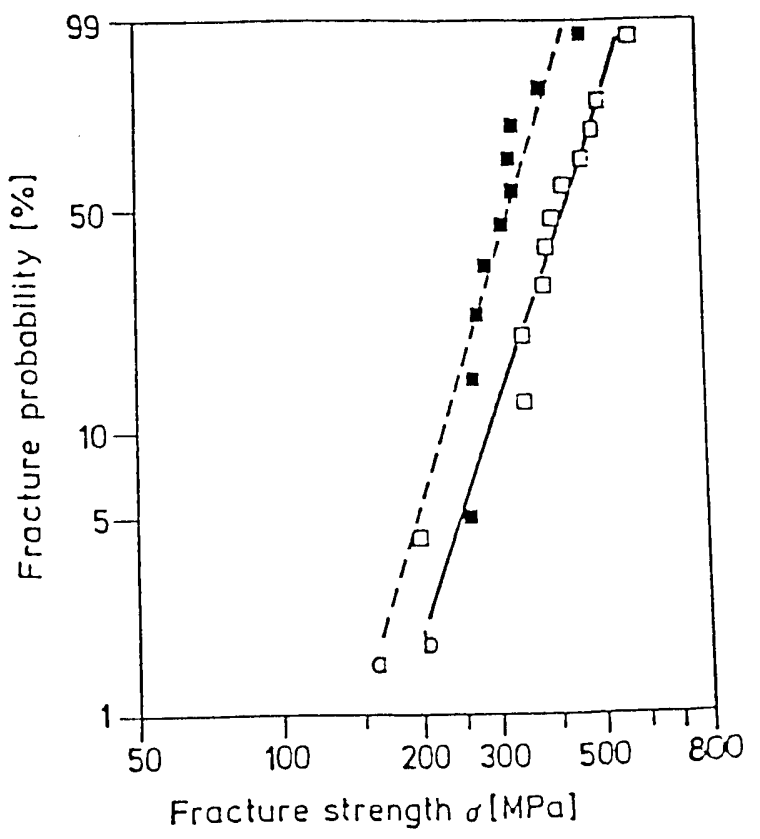

Fig. 6 Weibull-plot of fracture strength of sintered plates a: electrode side, b: solvent side (PAA-conc.: 1.3 wt. $-q$, alumina cont. : 40 wt. $-q$, voltage: $50 \mathrm{~V}$, sintering temp.: $\left.1640^{\circ} \mathrm{C}, 10 \mathrm{~min}.\right)$

\section{CONCLUSIOHS}

The electrophoretic deposition of alumina from a nonaqueous suspension was studied in the present paper. It could be proved, that electrophoresis is a suitable method for an agglomerate-free processing of submicron powders, because agglomerates can be separated directly from the suspension by sedimentation or centrifugation without additional processing steps. Furthermore the forming technique leads to a very homogeneous microstructure in the green compacts and offers the possibility to reduce the size of critical defects and improve the reliability of ceramic products. Further efforts will be done to optimize the deposition process and the properties of sintered product. 


\section{REFERENCES}

/1/ J. Hennicke and H. W. Hennicke: Formgebung in der Keramik - Formgebung durch Abscheidung aus Schlickern in elektrischen Feld. Handbuch der Keramik, Freiburg, 1981 p. 13 - 23 .

/2/ B. El-Jazairi, D. White and J. P. Roberts: On electrophoretic deposition of alumina from non-aqueous suspension. Sci. of Ceramics 9 (1977), p. $46-53$.

/3/ J. Mizuguchi, K. Sume, T. Muchi: A highly stable nonaqueous suspension for electrophoretic deposition of powdered substances. J. Electrochem. Soc: Electrochemical Science and Technology, 130 (1983), p. 18191825.

/4/ J. M. Andrews, A. H. Collins, D. C. Cornish and J. H. Dracass: The forming of ceramic bodies by electrophoretic deposition. Proc.Brit.ceram.Soc. 12 (1969) p. 211-229.

/5/ F. Harbach, R. Neef, H. Nienburg, private comunication

/6/ K. A. Egerer and G. Landsperg: Elektrophorese und Elektrosedimentation in nichtwäBrigen Suspensionen. Zeitschrift für Elektrochemie 59 (1955), p. 207-222. 


\title{
Ceramic Powder Processing Science
}

\author{
Proceedings of the \\ Second International Conference
}

\author{
Berchtesgaden (Bavaria) FRG
}

October 12-14, 1988

\author{
Edited by \\ H. Hausner \\ Technische Universität Berlin, FRG \\ G.L. Messing \\ The Pennsylvania State University, USA \\ S. Hirano \\ Nagoya University, Japan
}

Deutsche Keramische Gesellschaft

O Deutsche Keramische Gesellschaft e.V., 5000 Köln 90 (19 89 )

Druck: Offsetdruck H. Krannich, 5465 Erpel 